\section{NARRATIVAS SOBRE EL LUGAR. HABITAR UNA VIVIENDA DE INTERÉS SOCIAL EN LA PERIFERIA URBANA ${ }^{1}$}

Fabricio Espinosa Ortiz², Antonio Vieyra ${ }^{3}$, Claudio Garibay Orozco ${ }^{4}$

\section{Resumen}

El presente artículo busca analizar la experiencia de habitar en un fraccionamiento de la periferia urbana de Morelia, Michoacán, México. Si bien reconocemos la complejidad de estudiar el habitar cotidiano aquí nos delimitamos al análisis de tres dimensiones, la primera se refiere a cómo los habitantes a partir de sus propias narrativas valoran su vivienda y fraccionamiento actuales en relación a sus experiencias de habitar su vivienda y su fraccionamiento anteriores, la segunda se refiere al análisis del impacto que tiene en la vida cotidiana de los habitantes el vivir en una vivienda de interés social emplazada en un fraccionamiento de la

\section{NARRATIVES ABOUT PLACE. INHABITING SOCIAL HOUSING IN THE PERI- URBAN AREA ${ }^{1}$}

Fabricio Espinosa Ortiz ${ }^{2}$, Antonio Vieyra ${ }^{3}$, Claudio Garibay Orozco ${ }^{4}$

\section{Abstract}

This paper analyzes the experience of inhabiting a housing estate located in the peri-urban area of Morelia, Michoacan, Mexico. While we acknowledge the complexity behind the study of inhabiting practices we focus on the analysis of three dimensions: the first one is associated with dwellers and how they use their experiences to value their current dwellings in relation to their previous places of residence. The second dimension is related to the analysis of living in a housing estate and the impacts of these experiences on the everyday lives of dwellers. The third dimension offers an analysis of the 
periferia de la ciudad, y la tercera, al análisis de las relaciones vecinales y al uso que los habitantes le dan al espacio público del fraccionamiento. Lo anterior se analiza a través de entrevistas, recorridos de observación, observación participante y la aplicación de un cuestionario, con ello se busca entender la manera en que los habitantes del lugar recrean narrativamente la experiencia de habitar cotidianamente una vivienda de interés social en un fraccionamiento de la periferia urbana de una ciudad de tamaño medio.

PALABRAS CLAVE: NARRATIVAS; LUGAR; HABITAR; VIVIENDA DE INTERÉS SOCIAL; PERIFERIA URBANA

Fecha de recepción: 13-06-2014

Fecha de aceptación: 05-06-2015

1 El presente artículo se basa en la tesis “Vivienda de interés social y calidad de vida en Morelia, Michoacán" para optar al grado de Doctor en Geografía por la Universidad Nacional Autónoma de México (UNAM). La investigación doctoral fue financiada por el Consejo Nacional de Ciencia y Tecnología (CONACYT) a través de su programa de becas doctorales en el periodo 2010-2014. La misma fue premiada con mención honorífica en el Premio Internacional de Tesis de Investigación sobre Vivienda y Desarrollo Sustentable 2014.

2 México. Doctor en Geografía, Universidad Nacional Autónoma de México (UNAM). Correo electrónico: fespinosa@pmip.unam. $\mathrm{mx}$

3 Mexico. Investigador titular en el Centro de Investigaciones en Geografía Ambiental, Universidad Nacional Autónoma de México, campus Morelia. Correo electrónico: avieyra@ciga.unam. $\mathrm{mx}$.

4 Mexico. Investigador titular en el Centro de Investigaciones en Geografía Ambiental, Universidad Nacional Autónoma de México, campus Morelia. Correo electrónico: claudio@ciga.unam. $\mathrm{mx}$. relationships among neighbors and the use of public spaces on the part of dwellers. This is conducted through interviews, field visits, participant observation and a questionnaire. The goal of this research is to understand how the inhabitants of a given place recreate through narrative descriptions - the everyday experiences of inhabiting a housing estate in the peri-urban area of a medium-sized city.

\section{KEYWORDS: NARRATIVES; PLACE; INHABITING; SOCIAL HOUSING; PERI-URBAN AREA}

Received: 13-06-2014

Accepted: 05-06-2015

1 This paper is based on the dissertation "Social Housing and Quality of Life in Morelia, Michoacan" for the degree of Doctor in Geography, National Autonomous University of Mexico (UNAM). This dissertation was funded by the National Council on Science and Technology (CONACYT) as part of the 2010-2014 doctoral fellowship programs. This document was awarded honorary mention at the 2014 International Award on Theses on Housing and Sustainable Development.

2 Mexico. PhD. in Geography, National Autonomous University of Mexico (UNAM). Email: fespinosa@pmip.unam.mx

3 Mexico. Researcher at the Research Center on Environmental Geography, National Autonomous University of Mexico, Morelia.Email: avieyra@ciga.unam.mx

4 Mexico. Researcher at the Research Center on Environmental Geography, National Autonomous University of Mexico, Morelia.Email: claudio@ciga.unam.mx 


\section{Introducción}

La búsqueda de los gobiernos por mejorar la calidad de vida de la población está ligada a la vivienda, ya que es una de las necesidades humanas más importantes. Actualmente disponer de una vivienda es un lujo, en especial para las personas de bajos recursos, contrariamente de lo que señalan la mayoría de las legislaciones que la reconocen como un derecho ciudadano. En México, se ha pasado de un Estado benefactor comprometido con la provisión de diferentes bienes, como la vivienda, a un estado que concede estos compromisos a los agentes financieros como lo es el sector inmobiliario.

Esta concesión del Estado ha propiciado el crecimiento exponencial de la oferta de vivienda debido a los sistemas de producción de tipo industrial que han adoptado las empresas inmobiliarias privadas, las cuales fusionan un conjunto de prácticas que van desde construcción, desarrollo, financiamiento y promoción, y teniendo como eje articulador la producción de vivienda masiva se incorporan en proyectos que por sus dimensiones se tratan de verdaderas ciudades. Estas empresas para reducir sus costos e incrementar utilidades, construyen viviendas pequeñas, en terrenos pequeños, con materiales económicos y localizadas cada vez más alejadas de la ciudad donde el precio de suelo es más barato, lo que suma a la dificultad de abastecimiento de infraestructura, equipamientos y servicios de calidad, acordes al volumen y perfil de la población, todo en detrimento de la calidad de vida.

En relación a lo anterior abordamos el caso del fraccionamiento Villas del Pedregal ubicado al suroeste de la ciudad de Morelia, en el estado de Michoacán, sobre la carretera Morelia - Guadalajara, a una distancia aproximada de $13 \mathrm{Km}$ del centro urbano 5 . Villas del Pedregal inició su construcción en el 2006 y es el más grande del estado con 14,000 viviendas en una superficie de 100,000 m2., se conforma por 4 etapas y está planeada una nueva con 6000 viviendas más. En este texto nos enfocamos en las viviendas de interés social, que van de los 30m2 a los $42.5 \mathrm{~m} 2$ de superficie, y en darle la voz a los usuarios, quienes son los menos escuchados e indiscutiblemente los principales actores y afectados ante la incapacidad del Estado para enfrentar el problema de vivienda.

La investigación contempló revisión bibliográfica, recorridos de observación, entrevistas

5 Para los residentes de Villas del Pedregal las distancias varían entre $13 \mathrm{~km}$ y $15 \mathrm{~km}$ al centro urbano y entre $7.5 \mathrm{~km}$ y $9.7 \mathrm{~km}$ al periférico, dependiendo de la parte del fraccionamiento en donde tengan su vivienda.

revista invi № 84 / Agosto 2015 / Volumen № 30: 59-86 
semiestructuradas, observación participante y la aplicación de un cuestionario ${ }^{6}$. Se ejecutaron las mencionadas técnicas de octubre de 2011 a septiembre de 2012, en diferentes días y horarios, con el fin de atribuirles las diferentes condiciones que se presentan en la vida cotidiana, como las lluvias, inundaciones, el calor, el frio, el día, la noche, las festividades, las vacaciones, los tianguis, los lugares en donde juegan los niños, los caminos transitados, los espacios peligrosos, los espacios concurridos y los abandonados, entre otros eventos y lugares que influyen en los modos de habitar de los habitantes.

Con el periodo de un año, buscamos no limitarnos a una observación estática y parcial. El observar la articulación de los espacios del fraccionamiento con la ciudad en diferentes periodos del año nos permite movernos de esta parcialidad, a partir de la conexión de las prácticas cotidianas y las subjetividades en diferentes espacios y tiempos. Se trató de un planteamiento que nos permitió pensar la investigación en términos relacionales y en lugar de mostrarnos una realidad estática de unos cuantos días, permitió entrar en un entramado de

6 Se realizaron de manera intercalada 12 recorridos de observación y 12 entrevistas. Un recorrido y una entrevista al mes a diferentes horarios, a lo largo de un año. Además se decidió vivir en el fraccionamiento durante los meses de agosto, septiembre y octubre de 2012, y finalmente se aplicó un cuestionario a 100 hogares siguiendo el procedimiento propuesto por Hernández, Fernández y Baptista (2006, p. 244 - 246) para calcular la muestra. experiencias de habitar que cambian a lo largo del año, y que fueron necesarias para desarrollar una mirada que nos ofreciera un cartografía experiencial de los residentes.

El relatar experiencias de habitar como toda experiencia de vida se inscribe en la narrativa, y esta a su vez se ancla en una temporalidad ${ }^{7}$. Las narrativas son recuperables mediante las entrevistas y la observación participante, estas proveen de voz a los entrevistados, y permiten explorar las experiencias de vida de las personas en el tiempo ${ }^{8}$, como lo es el habitar una vivienda. Las categorías de análisis del habitar son construidas por las personas como resultando de sus prácticas cotidianas en interacción con el espacio y con otras personas. Así que las narrativas no pueden comprenderse fuera del contexto en que se encuentran los participantes de la narración, es decir, la familia y los vecinos en la búsqueda cotidiana de la satisfacción de sus necesidades.

La situación familiar de llegar a vivir al entorno periférico de la ciudad, en donde no se conoce a los vecinos, y en el que es necesario acondicionar y/o ampliar la vivienda, gestionar el acceso a ciertos

7 Arfuch, 2010, p. 87-89.

8 Gubrium y Holstein, 2008. 

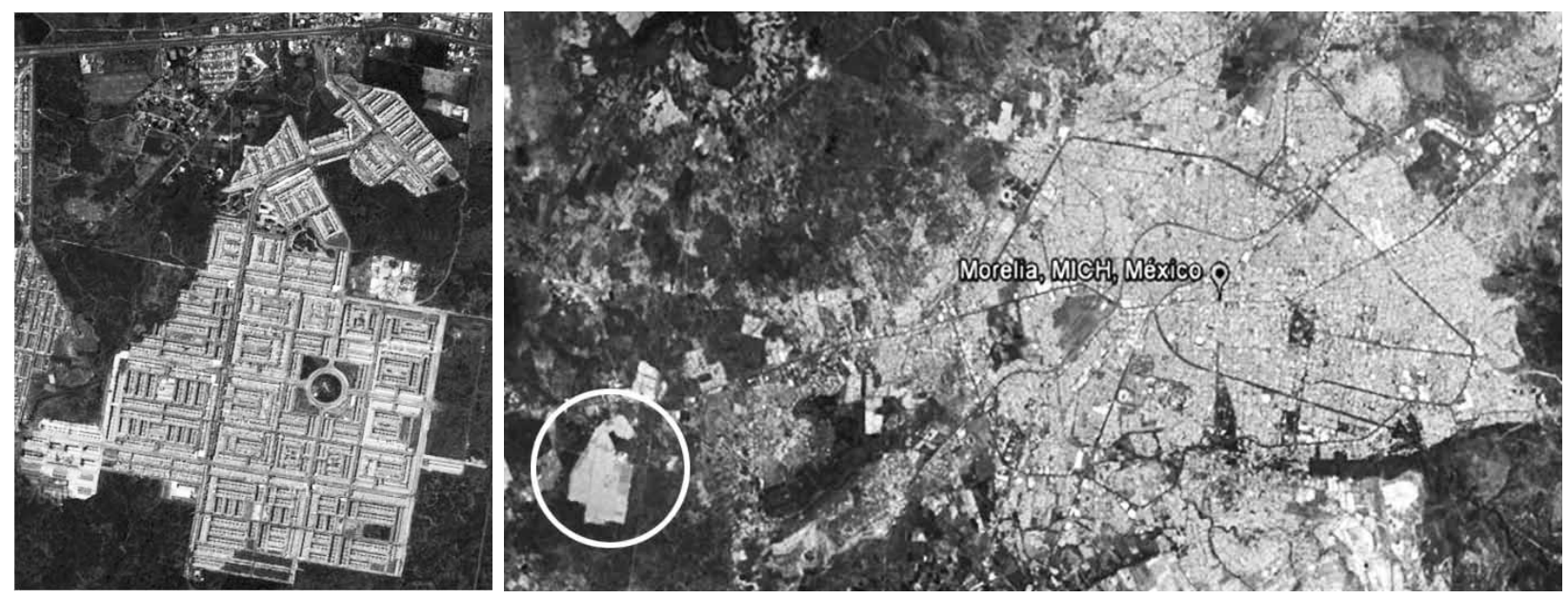

Fuente: Google Earth. 2013

servicios y al equipamiento, se refleja en la elaboración narrativa de las personas. Es decir, lo que ha ocurrido durante este proceso es una historia familiar en la que se enlazan experiencias positivas y negativas propias del habitar cotidiano. Se propone entonces que el espacio habitado puede examinarse desde su producción narrativa, y que narrar es una de las dimensiones del habitar. No son sólo palabras, son interpretaciones del pasado, presente y expectativas para el futuro. Los modos en que las personas narran sus experiencias influencian cómo perciben, recuerdan, valoran y se preparan para sus experiencias futuras ${ }^{9}$.

En este sentido, la vivienda y el fraccionamiento son lugares en constante transformación, colmados de narrativas individuales, pero también familiares y sociales en las que se conjugan tanto uniones y continuidades, como rupturas y discontinuidades que llegan a ser conflictos, logros y también fracasos, en una realidad compartida en la que se incluyen no solo las experiencias vividas

9 Daiute y Lightfoot, 2004, p. x-xiii. 
por el sujeto, sino también las de su familia y las del mundo social que también forman parte del mundo de los individuos ${ }^{10}$. De tal manera que vivir ahí, en un entorno como el de un fraccionamiento periférico de vivienda de interés social hacen del habitante un narrador privilegiado del lugar.

\section{El habitar}

El habitar es un proceso continuo e inacabado, ya que las personas mantienen distintas relaciones con los espacios que expresan cotidianamente en las maneras en que los usan, modifican y significan. Al hablar de habitar resulta inevitable hacer referencia al texto de Heidegger ${ }^{11}$, que plantea que el fin del construir es habitar y el hombre es en la medida en que habita, así del modo como somos los hombres es como habitamos.

Habitar significa reconocer el lugar, reconocerse en el, habitar-se ${ }^{12}$, lo que tiene ver con las diferentes repertorios y estrategias de cada individuo para expresar y exteriorizar su modo de vida. Habitando nos habitamos, ya que habitar no es sólo ocupar un espacio, es construirlo, y es así como se construye el ser y se construye el hábitat ${ }^{13}$. Habitar va más allá que residir, ya que implica, además de una

Schutz y Luckmann, 1977.

Heidegger, 1994, p. 115.

Acebo, 1996, p. 202.

Ekambi Schmidt, 1978, p. 36. relación funcional de las personas con el espacio para la realización de actividades, una vinculación significativa con el lugar y con las personas con las que se comparte de manera recursiva y "zonificada" conforme a espacio ${ }^{14}$. Se puede estar presente y utilizar un espacio, pero puede no habitarse, esto puede darse de diferente manera en las distintas escalas espaciales, por ejemplo, un individuo o grupo familiar puede habitar su casa y sentirse significativamente cómodo al interior de ella; y en contraste vivir y representar el fraccionamiento como un espacio hostil o por el contrario como un espacio al que se siente plenamente integrado; pero nunca le representará de manera indiferente, como un espacio sólo funcional; pues el tiempo vivido en interacciones positiva o negativa con sus vecinos le obligan a construir representaciones de ellos y por extensión del conjunto del fraccionamiento mismo. No así de los lugares de tránsito entre los espacios significativos (trabajo, casas de familiares, lugares de encuentro) donde el lugar es esencialmente funcional y las personas y cosas un escenario apenas significativo. De igual modo un individuo o grupo familiar puede representar su casa como un lugar incomodo, pobre, decepcionante, inferior a sus aspiraciones; en este caso su relación con su propia casa no será meramente 
funcional, como la que tiene un viajero en un hotel, sino como un espacio significadamente hostil que habita significativamente como una ruptura entre lo que es y lo que aspira a ser.

En este tipo de tensiones se puede "residir" sin habitar una vivienda cuando el espacio se utiliza únicamente para desempeñar funciones de reproducción social ${ }^{15}$; pero siempre y cuando el individuo o el grupo signifique ese "residir" como una estancia provisional; gobernado por un imaginario de futuro próximo en el que se moverán a la vivienda definitiva en la que imagina merece estar. Si las expectativas se frustran el residir se transformara en un habitar hostil, o en su caso en un habitar resignado a las animadversiones que ve en su vivienda y entorno.

El habitante se apropia del espacio en un proceso de adaptación mutuo, por un lado, el espacio lo influye, condicionándolo en su práctica; y por otro, para poder adaptarse a este espacio, el habitante intenta superar sus condicionantes transformándolo formal y conductivamente. Estaríamos así, frente a una dinámica en la cual el espacio ha sido creado y recreado constantemente, dinámica que define por sí misma el fenómeno de habitar. Es así que el habitar una vivienda nos vincula no solo a estar

15 Duhau y Giglia, 2008, p. 24. presente en ella en relación con su materialidad, sino también en relación con su contenido como su mobiliario y sus ocupantes. Habitar va más allá que el hecho de estar localizado en un espacio, ya que alude a las prácticas cotidianas que articulan la presencia de los sujetos en el espacio en relación con otros sujetos ${ }^{16}$.

El esquema espacial del habitar tiene como centro a la vivienda, la cual se enmarca en realidades espaciales que constituyen un complejo entramado de sentidos, contactos y flujos de relaciones que generan identidad de las personas para con el lugar, es ahí donde estas reconocen sus deseos, logros y fracasos, donde se siente segura y tiene experiencias agradables y desagradables. El habitar tiene múltiples acepciones como es la de protección, en el sentido de amparo o abrigo ${ }^{17}$. O la de cuidado ${ }^{18}$, ya que el que cuida la tierra a la vez la habita, al igual que la vivienda que se habita en la medida que se cuida. Sin embargo estas sensaciones de protección y cuidado se cuestionan cuando la precariedad de la vivienda y el espacio público son las características más evidentes de varias ciudades y cuando el miedo y la inseguridad son parte de las experiencias cotidianas de la sociedad ${ }^{19}$.

Ibid.

Bachelard, 2000.

Abalos, 2005, p. 47-48.

Beck, 1998. 


\section{Del espacio a la conformación del lugar}

Preguntarse cómo es el proceso en que los espacios devienen lugares supone profundizar en las relaciones y vínculos que se establecen entre las personas y los espacios. El lugar implica un espacio y un sujeto que posee la capacidad de apropiarse de él para habitarlo, de esta manera podemos considerar el lugar como el sustantivo en el que recae la acción del verbo habitar. Tuan sugiere que el lugar no tiene ninguna escala asociada a él, pero es creado a través de la relación emocional de las personas ${ }^{20}$. Cuando se habita un espacio se construye un lugar, esto se da simultáneamente en la medida en que se apropia. Es decir, el espacio que se habita a la vez se apropia y se convierte en lugar. Espacio y lugar tienen una relación tan estrecha que no pueden definirse por separado ${ }^{21}$. Espacio procede del latín spatium que significa apertura y amplitud. Lo que comienza como un espacio se vuelve lugar en la medida en que se conoce y valora, de esta manera, el lugar acota el espacio, le proporciona límites y lo dota de una materialidad particular. El lugar se asocia al pasado, por tanto nostálgico, referente a la apropiación y el arraigo, por su parte el espacio se asocia al presente y futuro, al progreso

20 Tuan, 2001.

21 Ibid., p. 6 y lo global, el espacio se compone de lugares y los lugares se inscriben en el espacio ${ }^{22}$.

Las particularidades de lo local y la variedad de lugares están siendo sustituidos por los espacios globales, homogéneos, indiferenciados, sin identidad $^{23}$. Una manera de recuperar la diversidad de significados y emociones que las personas manifiestan en los lugares, es mediante sus narrativas, el lugar ellos lo hacen, place making, y al hacerlo lo conciben suyo, le dan sentido en una construcción siempre en curso, que además es recíproca, ya que los lugares construyen a las personas e infieren en su sentir, sense of place ${ }^{24}$.

Es también el lugar ubicación y entorno, es decir un ¿dónde está?, referente a su localización, y un ¿cómo es?, referente al contexto físico material en donde se desarrollan las relaciones sociales, ambos referentes existentes aun y cuando los lugares sean imaginados, porque las personas construyen sus propios lugares articulando lo real y lo imaginario $^{25}$. El lugar tiene una relación inherente con la identidad porque en el lugar el hombre se identifica a sí mismo, la vivienda como lugar influye y refleja la vida de las personas. Cuando la vivienda

\footnotetext{
22 Agnew, 2005, p. 85-86.

23 Hardt y Negri, 2000, p. 40-45.

24 Holloway y Hubbard, 2001.

25 Bailly, 1989.
} 
se apropia configura los estados de ánimo de sus habitantes, y refleja su yo ${ }^{26}$.

Sin embargo, la identidad del lugar no está solamente inscrita en él, sino que está compuesta también por relaciones externas. Es decir, no hay lugares que por sí solos generen identidad, ni tampoco identidades predeterminadas, sino que los lugares adquieren sus identidades en buena parte por la relación con otros lugares. Las realidades de la vida cotidiana de las personas se constituyen por una geografía de vínculos y de contactos, con extensiones múltiples y diversas, algunas de las cuales relacionadas con lugares del pasado como la casa de la infancia, o incluso con lugares muy distantes entre sí, como la casa durante la estancia en otro país, o sea que la identidad de un lugar siempre está en proceso de formación y modificación en base a nuestras experiencias de habitar en diversos lugares a lo largo de nuestra vida ${ }^{27}$.

Desde la perspectiva de la experiencia, un lugar se diferencia del espacio en términos de familiaridad y el tiempo, este requiere del proceso de familiarizarse con él, de conocerlo y habitarlo, lo que demanda cierto tiempo. A medida que recorremos cualquier parte del mundo pasamos de un lugar a otro, y si no nos detenemos, si sólo cruzamos, perderemos la noción de sus características

26 De Botton, 2006.

27 Massey, 2004. y cualidades. En este sentido podemos decir que nos estaremos moviendo a través del espacio. Esto incluso nos puede suceder en nuestra propia casa, podemos usarla pero sentirla ajena e incluso insatisfactoria, puede parecernos más un espacio que ocupar que un lugar para habitar ${ }^{28}$. Desde la seguridad y estabilidad que brinda el lugar, somos conscientes de la apertura y la libertad que brinda el espacio. Además si pensamos en el espacio como aquello que brinda libertad de movimiento, entonces pensamos en el lugar como la posibilidad de hacer pausas, las cuales permitirán transformarlo en lugar ${ }^{29}$.

\section{La vivienda como el lugar para formar un hogar}

Casi todos ocupamos una vivienda, ahí crecimos y desplegamos nuestra vida, ahí nos protegemos, sembramos la confianza y nos sustraemos hacia nosotros mismos, es ahí donde hacemos las pausas necesarias para pensar y planear nuestra vida, ahí echamos raíces, nos arraigamos, hacemos lugar y fundamos un hogar ${ }^{30}$.

La vivienda alberga connotaciones y experiencias que el habitarla le confiere, ahí se enmarca el

\footnotetext{
28 Sack, 1997, p. 16.

29 Tuan, 2001.

30 Uzcátegui, 2011.
} 
proyecto cotidiano de las personas para ganarse la vida $^{31}$. Sin casa el hombre sería un ser disperso ${ }^{32}$ porque la casa fija a las personas, es el lugar que el hombre construye a lo largo de su vida y en el que se aísla por el tiempo absorbido en ver televisión y navegar en internet, entre otras prácticas que han exacerbado la separación del espacio público con el privado ${ }^{33}$.

La vivienda no puede ser entendida únicamente como la residencia común de personas que comparten gastos y obligaciones, es un hogar que se construye vivencialmente, una vivienda se convierte en hogar en la medida en que un espacio se convierte en lugar, un hogar está imbuido de intimidad, seguridad y pertenencia, aunque también puede estarlo de miedo, inseguridad y violencia, situaciones que tienen un anclaje espacial multiescalar ${ }^{34}$.

El hogar es el sistema de coordenadas que nos orienta en el mundo, es el lugar de donde venimos y pertenecemos ${ }^{35}$. Muchas personas no tienen un hogar aunque tengan una vivienda donde refugiarse, y una vivienda no será un hogar sólo por ocuparse, un hogar es la vivienda más la gente que la habita y los objetos que guarda ${ }^{36}$. Al hablar del

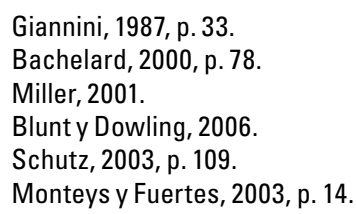

hogar estamos obligados a introducir la subjetividad de los residentes, ya que las relaciones, emociones, sentimientos y recuerdos que se mantienen con el hogar en que se ha crecido, son imborrables. El hogar es una condición compleja y difusa. Que integra memorias, imágenes, deseos, miedos, pasado y presente; comporta un conjunto de rituales, ritmos personales y rutinas cotidianas; constituye el reflejo del habitante, de sus sueños, sus esperanzas, sus tragedias o su memoria ${ }^{37}$.

Por supuesto que el hogar es el lugar en donde las familias satisfacen sus necesidades, dicha satisfacción puede ser facilitada por un diseño en la vivienda acorde a la composición familiar y los modos de habitar, si no es así, el espacio no lograría conformarse como lugar y la vivienda no se constituiría como un hogar al no cubrirse satisfactoriamente las necesidades familiares, así la "casa real", no corresponderá con la "casa imaginaria" llena de ilusiones, deseos y expectativas ${ }^{38}$.

Dada la complejidad del objetivo de la investigación de explorar las experiencias de habitar de los habitantes de las viviendas de interés social en el fraccionamiento Villas del Pedregal, a partir de sus propias narrativas, se enfatizó en tres dimensiones

37 Gili, 1999, p. 7.

38 Ortiz, 1984. 
interrelacionadas: la primera se refiere al valor que los habitantes otorgan a la vivienda y fraccionamiento actuales en relación a sus experiencias de habitar los anteriores, la segunda se refiere al impacto que tiene el emplazamiento periférico de Villas del Pedregal en la vida cotidiana de sus habitantes, y la tercera se refiere al análisis de las relaciones vecinales y al uso que se da al espacio público del fraccionamiento. La investigación se llevó a cabo utilizando una complementariedad de enfoques metodológicos cualitativos y cuantitativos, para comprender los significados que los habitantes depositan en su vivienda y fraccionamiento, y que guían sus modos de habitar. Dentro de esta metodología se utilizaron una variedad de técnicas que incluyen entrevistas semiestructuradas y recorridos de observación, que se complementaron con observación participante, y finalmente con la aplicación de un cuestionario.

\section{Modos de habitar en Villas del Pedregal}

Con base en los resultados de la encuesta aplicada y el análisis de las entrevistas, se detectó el perfil de la población del fraccionamiento Villas del Pedregal, en este viven mayoritariamente matrimonios jóvenes con la edad promedio de 34 años en el caso de los padres y de 32 años en el caso de las madres de familia. En cuanto a la edad de los hijos, destaca el rango de 6 a 12 con el 33.63\% del total de las niñas y el $32.98 \%$ en el caso de los niños.

En relación al trabajo de los padres, el 36.17\% lo hacen como empleados de empresas privadas, como guardias de seguridad, operadores de maquinaria, taxistas, vendedores, intendentes, etc. El 17.02\% como empleados de gobierno y el $12.76 \%$ como profesionistas. En porcentajes menores, existen comerciantes establecidos, docentes, obreros de la construcción, vendedores ambulantes, pensionados, estudiantes y un $8.51 \%$ de ellos son desempleados. Es importante señalar que el $10.63 \%$ de los padres cuenta con empleo eventual. En cuanto el trabajo de las madres, un $37.50 \%$ son amas de casa, un $25 \%$ empleadas de empresas privadas, un $11.45 \%$ de empleadas de gobierno, un $10.41 \%$ de profesionistas, y en porcentajes menores existen comerciantes, docentes, vendedoras, estudiantes y pensionadas. El 16.66\% de las madres declaró tener trabajo eventual, no obstante gran parte de las madres que declararon ser amas de casa, aportan al ingreso familiar vendiendo en la propia vivienda, fruta, dulces, galletas, ropa, zapatos, productos de belleza o bien ofreciendo servicios de corte de cabello, maquillaje, y hasta cuidado de niños.

En cuanto a los ingresos promedio mensuales, los padres perciben 6170 pesos y las madres 3520 pesos. El $18.33 \%$ de ellas percibe menos del salario mínimo que para Michoacán está estipulado en 61.38 pesos diarios, es decir 1902 pesos 


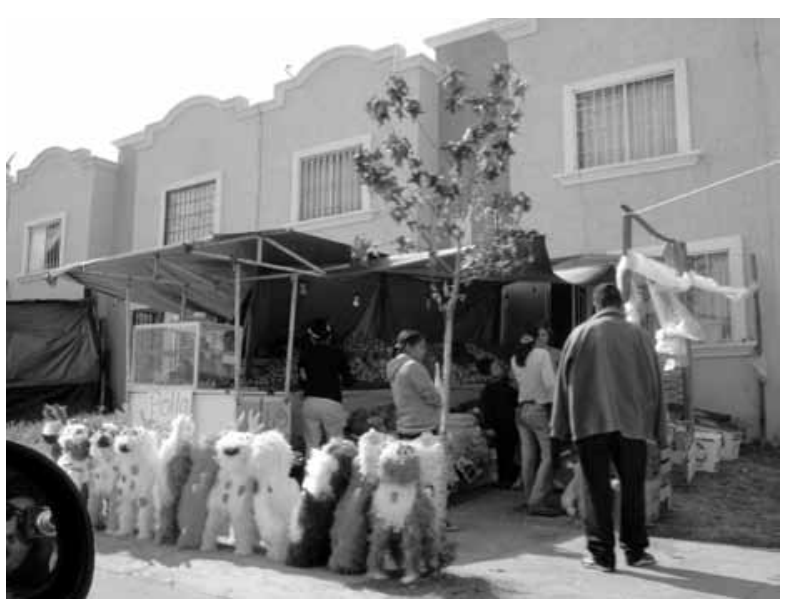

Fuente: Autores

mensuales. Lo anterior se debe en parte a que el $39.58 \%$ de mujeres se dedican exclusivamente al hogar y el $16.66 \%$ trabaja sólo eventualmente. El ingreso promedio por hogar aumenta, ya que en el $40 \%$ de los hogares encuestados ambos padres trabajan, además de que en el $17 \%$ de estos se ha incorporado otro miembro de la familia al mercado de trabajo, quedando el ingreso promedio en 7362 pesos, ingreso que se encuentra por dejado de los 8019 pesos que según la Organización Internacional del Trabajo es el ingreso promedio mensual en México (tabla 1).

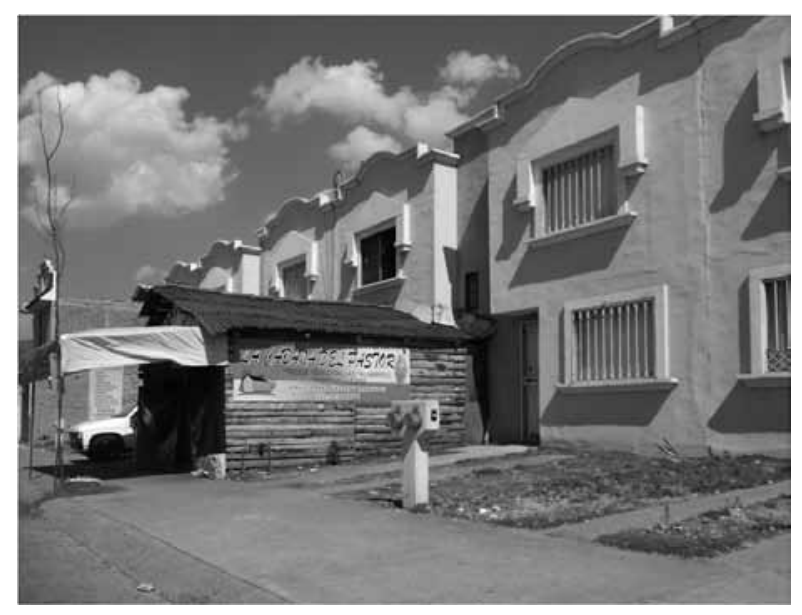

\section{La vivienda anterior y la vivienda actual}

El $77 \%$ de los hogares encuestados proviene de colonias populares colindantes al centro histórico de Morelia, el 19\% proviene de otras partes de Michoacán o de otros de estados como Guerrero, Guanajuato, Estado de México, Chihuahua y Baja California, e incluso el 2\% manifestó que su residencia inmediata anterior fue en los Estados Unidos, solamente el $1 \%$ procede de un fraccionamiento 
TABLA 1. INGRESOS MENSUALES DE LOS RESIDENTES

\begin{tabular}{lllll}
\hline INGRESO $\$$ & PADRES $\%$ & MADRES $\%$ & OTROS FAMILIARES $\%$ & HOGARES \% \\
\hline Menos de 1902 & 6.09 & 18.33 & 35.29 & 11,26 \\
\hline De 1903 a 3000 & 13.41 & 21.66 & 23.52 & 16.90 \\
\hline De 3001 a 4500 & 17.07 & 23.33 & 41.17 & 19.71 \\
\hline De 4501 a 6000 & 23.17 & 15.00 & 17.64 & 19.71 \\
\hline De 6001 a 7500 & 15.85 & 8.33 & 5.88 & 12.67 \\
\hline De 7501 a 9000 & 10.97 & 6.66 & - & 9.15 \\
\hline De 9001 a 12000 & 8.53 & 5.00 & - & 7.04 \\
\hline De 12001 a 15000 & 4.87 & 1.66 & - & 3.52 \\
\hline
\end{tabular}

Moneda: pesos mexicanos

Fuente: Autores

similar a Villas del Pedregal. El 46\% de las familias residían en la casa de sus padres o suegros, 34\% rentaba, $14 \%$ vivía en una casa prestada, y solo un $6 \%$ en una vivienda propia. En cuanto a la disposición de servicios el 3\% manifestó que no contaba con agua y el $4 \%$ con drenaje. Por otra parte, el $18 \%$ de las viviendas anteriores tenían más de tres habitaciones con un promedio de 4.8 personas por vivienda, a diferencia de los 4.2 de la vivienda actual.

"Las casas están chiquitas y la verdad es que sí están lejos de Morelia, pero la ventaja que le vemos con mi marido es que esta ya es de nosotros, bueno la estamos pagando pero está mejor que vivir con mi suegro, eran buena gente y no se metían con nosotros pero estábamos en su casa y eso sí está incomodo, estar en una casa que no es tuya”. (Martha ${ }^{39}, 27$ años, residente de la segunda etapa).

Las experiencias previas inmediatas o lejanas de las personas forman parte de su comprensión del mundo ${ }^{40}$. El habitar la vivienda de la infancia o donde se formó una familia evoca recuerdos e imágenes que son revividos al habitar la vivienda actual. En una suerte de poética del pasado, el hombre habita su vivienda anterior en sus recuerdos, sus sueños y deseos ${ }^{41}$. En este sentido las

39 Los nombres de los entrevistados y encuestados son seudónimos, con el fin de preservar su identidad.

40 Schutz y Luckmann, 1977, p. 28.

41 Bachelard, 2000. 
experiencias espaciales pasadas se entrecruzan con las actuales, y el considerar este cruce en las narraciones de los entrevistados, nos permite superar un presentismo sin vínculos temporales.

Un lugar evoca otro lugar, una vivienda evoca a otra, y esas evocaciones también forman parte de una trama de sentido ${ }^{42}$. Por ejemplo, si la vivienda anterior era muy amplia y se ubicaba en una zona bien equipada y segura, esas evocaciones se anclan en el pasado vivido por el sujeto e indiscutiblemente influyen en su forma de ver el mundo en el presente y claro que también en el habitar su vivienda actual, en donde reconocerá sus espacios y la zona en que se ubica en relación a un parámetro comparativo con su vivienda y fraccionamiento anteriores, en este sentido podría percibir su vivienda actual como muy pequeña, ubicada en una zona sin los equipamientos suficientes y sin la seguridad deseada.

La comparación entre la vivienda anterior y la vivienda actual fue inevitable al preguntarles a las personas sobre las condiciones de la vivienda actual. Según palabras de una vecina entrevistada:

"[...] aquí el agua sale sucia cosa, que no pasaba allá en Trincheras (nombre de la colonia anterior), en casa de mis suegros, lo que pasaba allá era que no usaba el agua a gusto, aunque les cooperábamos, no era lo mismo, aquí es mi casa y es mi agua, y yo la uso como quiera y nadie

42 Lindón, 2007. me dice nada" (Rosa, 29 años, residente de la segunda etapa).

La narración de las experiencias pasadas de los habitantes incluyen los aspectos que les gustaban y disgustaban de su vivienda y colonia, estas experiencias forman parte del Background de las personas y repercuten en sus prácticas ${ }^{43}$. A este respecto, el $72 \%$ de los residentes manifestó que les gustaba su colonia anterior por distintas razones como la buena ubicación, la cercanía con la escuela de los hijos y con los lugares de abasto, entre otros aspectos, aunque el 28\% manifestó aspectos que les disgustaba la inseguridad, las inundaciones, la falta de áreas verdes, entre otros. Estas virtudes y defectos de la colonia anterior forman parte de la experiencia de habitar de los residentes y vienen al presente a partir de que se instalan en su nueva vivienda.

Las causas que orientan a las personas a establecerse en la periferia urbana alejada de los satisfactores que ofrece la ciudad, son parte de un imaginario colectivo que emerge en decisiones y prácticas, como la de tener casa propia, no pagar renta o independizarse, todo esto tuvo como antecedente la decisión de dejar una vivienda compartida en una zona con mejores equipamientos que les facilitaba los desplazamientos cotidianos. La subjetividad espacial que acompaña a dichas estrategias se concreta en distintas formas de habitar. No es lo

43 Taylor, 2006, p. 39. 
mismo que el imaginario de los habitantes que se movilizan a la periferias forme parte de un proyecto optimista de búsqueda de "una vida mejor" con la convicción de formar parte de una comunidad, a que sea porque no tuvo opción y las circunstancias los orillaron a llegar ahí. Las distintas circunstancias que formaron parte del proceso de adquisición de la vivienda definitivamente inciden en la identificación y sentido de pertenencia del individuo con esta y en la valoración de su calidad de vida en ese contexto ${ }^{44}$.

Una vez que las personas residen en su nueva vivienda, la anterior sigue presente y funciona como marco de referencia desde el cual se construyen los modos de habitar ${ }^{45}$. En relación a esto, es común que los vecinos manifiesten encontrarse en una situación de progreso en relación a situación anterior.

"Con mis suegros estábamos bien, sí cabíamos bien en la casa, nos trataban bien, teníamos nuestro propio cuarto, no nos faltaba nada, pero pues no era nuestra casa y pues no teníamos tanta libertad, teníamos que ajustarnos a todo lo que ellos decían" (Josefa, 25 años, residente de la segunda etapa).

El 65\% de los encuestados manifestó como las razones más recurrentes para dejar su vivienda anterior, el deseo de progresar, tener una casa propia,

44 Hiernaux, 2005.

45 Lindón, 2005.

\section{TABLA 2. RAZONES PARA DEJAR LA VIVIENDA} ANTERIOR

\begin{tabular}{ll} 
Tener casa propia & $20 \%$ \\
\hline No estaba a gusto & $7 \%$ \\
\hline No cabíamos & $6 \%$ \\
\hline Para el bienestar de la familia & $9 \%$ \\
\hline Para progresar & $14 \%$ \\
\hline Porque me pidieron la casa & $7 \%$ \\
\hline Para no molestar & $4 \%$ \\
\hline Porque tenía el crédito & $7 \%$ \\
\hline Por divorcio & $2 \%$ \\
\hline Para mejorar & $10 \%$ \\
\hline Para tener calidad de vida & $2 \%$ \\
\hline Independizarme & $3 \%$ \\
\hline Estaban amontonados & $5 \%$ \\
\hline No tenía privacidad & $4 \%$ \\
\hline
\end{tabular}

Fuente: Autores

no pagar renta o independizarse. Si bien la mayoría de ellos manifestó dejar esa vivienda en busca de una mejor situación para su familia, en el 35\% de los casos se trata de una situación dada por las condiciones en que vivían, es decir, tuvieron la necesidad de dejar la vivienda porque no estaban a gusto, se las pidieron, no tenían espacio suficiente o porque no les gustaba (tabla 2). 
"[...] allá teníamos todo cerca, la guardería, la escuela, el mercado, el trabajo y todo, pero pues ya era justo y necesario cambiarnos, ya me había dicho mi mamá que buscara otro lugar, es que ya llevábamos como cinco años viviendo ahí con mi marido y los niños, bien apretados, y pues no les dábamos tranquilidad a mis papas que ya están grandes" (Juana, 30 años, residente de la tercera etapa)

Situaciones como estas, tanto negativas como positivas son propias del habitar la vivienda, y juegan un papel importante cuando las personas deciden residir en una nueva vivienda y comienzan a establecer formas particulares de habitarla, ya que emerge en decisiones y acciones concretas, como el poner un pequeño negocio, construir un local, ampliar o remodelar la vivienda, el hacer ejercicio en la sala y adaptarla como gimnasio, o como el lugar de trabajo, entre otras intervenciones en los usos de los espacios.

\section{Emplazamiento periférico del fraccionamiento y su impacto en la vida cotidiana de sus residentes}

La ubicación periférica del fraccionamiento de Villas del Pedregal genera altos costos para sus residentes ya que ante la escasez de equipamientos en la zona, requieren trasladarse cotidianamente para realizar sus actividades laborales, educacionales,
TABLA 3. TIEMPO DE TRASLADO AL TRABAJO (IDA Y VUELTA)

\begin{tabular}{ll} 
Media hora & $3 \%$ \\
\hline Una hora & $18 \%$ \\
\hline Hora y media & $6 \%$ \\
\hline Dos horas & $58 \%$ \\
\hline Dos y media & $4 \%$ \\
\hline Tres horas & $9 \%$ \\
\hline Más de tres horas & $2 \%$ \\
\hline
\end{tabular}

Fuente: Autores

recreacionales, entre otras, esta situación agudiza la separación entre la vivienda y los equipamientos de la ciudad y afecta a los residentes en su búsqueda cotidiana de la satisfacción de sus necesidades.

"Faltan aquí más escuelas, es el problema que veo yo aquí, en la que hay todos quieren entrar y pues está saturada, yo tengo que llevar a mis hijos a otra escuela, pero pues si necesito tomar doble camión y pues los dos hijos y mi pasaje si sale caro y luego hay que ir por ellos, ya que estén más grandes que se vengan solos pero ahorita si necesito ir" (Norma, 36 años, residente de la tercera etapa).

Además de la distancia, el tráfico lento, las malas condiciones del transporte y de las vialidades, propician que los habitantes de Villas del Pedregal consuman mucho tiempo en sus traslados, llegando a cubrir el 73\% de los encuestados mas de dos horas diariamente (tabla 3). 
Al tiempo que las personas están obligadas a perder en su movilidad cotidiana con situaciones como esperar el transporte público, transbordar y cambiar de ruta, y la demora en llegar a sus diferentes destinos. Lefebvre le llama tiempo compulsivo ${ }^{46}$, y lo señala como un gran vacío entre el tiempo de trabajo y el tiempo libre, que incluso tiende a ser mayor que estos, con lo que se reduce la oportunidad de realizar cotidianamente algunas practicas como estudiar, cocinar y comer en casa, convivir con la familia o descansar adecuadamente.

"Nosotros visitamos a mis padres mínimo una vez a la semana les llevamos a los niños para que los vean, porque es bueno que los niños convivan con sus abuelos, pero pues nos queda lejos, varias veces se nos hace tarde y pues ya nos dicen mis papas que nos quedemos ahi y pues sí nos quedamos, sirve que no gastamos en taxi, tan caro de noche" (Carol, 31 años, residente de la cuarta etapa).

El análisis de la movilidad no será completo si nos limitamos a considerar la duración en el traslado hacia los lugares donde las personas llevan a cabo las actividades relacionadas con la educación, el abasto, el esparcimiento, la salud, entre otras. También es necesario contemplar los costos, el tiempo compulsivo y la reiteración de la práctica, con sus obstáculos, limitaciones y demás inconvenientes,

46 Lefebvre, 1971, p. 53 a lo largo de la semana, a lo largo de varios meses y años ${ }^{47}$.

"El camión cuesta 7.00 pesos pero ese te deja en el monumento Lázaro Cárdenas (zona centro) así que hay que transbordar, para ir al trabajo, mi esposo trabaja en el centro comercial de la Américas, así que se gasta los 7 pesos más otros 5 pesos, un total de 12.00 pesos de ida y otros 12.00 de regreso, aunque a veces en la noche que por algo se le hace tarde le ha tocado pagar taxi, hijole y ese si le cobra como 70.00 pesos más o menos" (Olga, 32 años, residente de la segunda etapa).

En Villas del Pedregal el 57\% de las familias manifiesta transportarse en automóvil propio, de las cuales, el 43\% tiene un automóvil y el 11\% manifiesta tener dos. El padre de familia es el que usa más el automóvil para trasladarse diariamente al trabajo, y en muchas ocasiones regresa hasta la noche, porque no cuenta con el tiempo suficiente para ir y regresar, además de que le implica un costo elevado el hacer el recorrido. Las madres de familia y los hijos manifiestan utilizar más el transporte público para actividades de abasto y para ir a la escuela respectivamente.

"[...]el coche lo usa mi marido toda la semana para ir al trabajo, yo no se manejar, pero no importa, pues no salgo mucho, solo algún sábado o domingo visito a mi familia, aunque procuro regresar temprano para alcanzar camión, porque el taxi si está muy caro para acâ" (Luisa, 29 años, residente de la tercera etapa).

47 Lindón, 2006, p. 375. 
Si hacemos una comparación con la situación que impera en el resto de la ciudad de Morelia, tenemos que la posesión de vehículo por vivienda es significativamente más alta que el promedio de 0.68 automóviles/vivienda para el caso de Villas del Pedregal con un promedio de 1.19 automóviles/ vivienda ${ }^{48}$.

"[...] la desventaja para mí es lo retirado y que no tengo coche, yo trabajo en una farmacia ahi por Camelinas (zona centro) y pues no me da tiempo de regresar a comer, tengo que comer en la calle y pues ahí el gasto, aunque casi sale lo mismo gastar en comida que en el traslado" (José, 35 años, residente de la segunda etapa).

La ubicación del fraccionamiento en conjunto con el alto costo, la duración del traslado, las condiciones del trafico, el transporte, las vialidades y los bajos ingresos de los residentes, propician su aislamiento, ya que resulta caro y tardado el visitar familiares y amigos, debilitando con esto las redes afectivas. Ante esta situación sólo se hacen los traslados necesarios, como son hacia el trabajo y la escuela.

"Nosotros tratamos de visitar a mis padres mínimo una vez a la semana y llevarles a los niños para que los vean, porque es bueno que los niños convivan con sus abuelos, pero pues nos queda lejos, varias veces se nos hace tarde y pues ya nos dicen mis papás que nos quedemos ahi y pues si nos quedamos, sirve que no gastamos en taxi,

48 Gobierno Municipal de Morelia, 2012 -2015. tan caro de noche" (Ricardo, 36 años, residente de la cuarta etapa).

El 21\% de los residentes entrevistados manifestó estar inconforme con la ubicación del fraccionamiento y con las dificultades que esto les trae, sin embargo un $66 \%$ de ellos manifestó que el motivo para sobrellevar esta desventaja, es que ahora no pagan renta y poseen una vivienda.

"[...] pues fijese que yo siento que mejoramos de donde vivíamos, eso de pagar una rentita no te da chance de nada, ahi se te va mucho dinero si le sumas, y pues ahora aunque no nos sobra el dinero ni mucho menos, a veces nos vamos al cine, a cenar y pasear con los niños" (Julia, 26 años, residente de la tercera etapa).

La posibilidad de tener una casa propia aminora las desventajas que pudiera tener una vivienda de dimensiones reducidas, con una cantidad insuficiente de habitaciones para cubrir las necesidades de la familia, y ubicada en un fraccionamiento alejado y sin el equipamiento suficiente. Y como dicen Berger y Luckmann ${ }^{49}$, toda actividad humana está sujeta al acostumbramiento. Y en este acostumbramiento la vivienda, el fraccionamiento y en general las condiciones de vida se aceptan inevitablemente aun y no siendo las más óptimas. 


\section{Las relaciones vecinales y uso del espacio público}

Los poseedores del capital son capaces de desplazarse por la ciudad libremente a diferencia de aquellos sectores segregados que deben conformarse con el espacio en donde les tocó vivir, quienes residen allí lo hacen porque no tienen muchas opciones y al final eligen lo que está a su alcance, y esto de ninguna manera es garantía de que los residentes se encuentren satisfechos con su vivienda, ni con sus vecinos, ni tampoco es garantía de que el fraccionamiento sea exitoso en el largo plazo ${ }^{50}$.

[...] sí hay problemas, sí hay inseguridad, pero pues es como en todos lados y ya uno se acostumbra, como uno no se mete con nadie, además en toda la ciudad hay inseguridad, bueno si quisiera estar bien seguro pues viviría en Altozano (fraccionamiento destinado a los sectores altos) pero pues como ahí es para los ricos ahí sí hay seguridad (José, 35 años, residente de la segunda etapa).

Esta situación es característica en muchos de los fraccionamientos de vivienda social ubicados en la periferia de las ciudades en donde sus habitantes están ahí, no por su ubicación, ni por los equipamientos y servicios que se ofrecen, sino porque es lo que pueden pagar. La imposibilidad de elegir en dónde vivir, con quien vivir y en qué tipo de

50 Westbury, 2007.
TABLA 4. ¿CONOCE A LOS VECINOS DE SU CALLE?

\begin{tabular}{ll} 
No los conoce & $23 \%$ \\
\hline Solo conoce a los de los lados & $8 \%$ \\
\hline Conoce a muy pocos & $21 \%$ \\
\hline A los de enfrente & $6 \%$ \\
\hline Conoce algunos de vista & $12 \%$ \\
\hline Conoce a varios de vista & $5 \%$ \\
\hline Saluda a algunos & $11 \%$ \\
\hline Con algunos se visitan & $4 \%$ \\
\hline Frecuentan seguido a algunos & $3 \%$ \\
\hline Varios son sus amigos & $3 \%$ \\
\hline
\end{tabular}

Fuente: Elaboración propia

vivienda, se ha convertido en un eje de malestar cotidiano.

"Con los vecinos nos saludamos bien, cuando vamos al abarrote (comercio de viveres) ahi te los encuentras, pero nada más, no convivimos, ni hacemos reuniones y menos fiestas, ni nada más, cada quien está en su casa y ahí hace lo que quiere, y gracias a Dios me tocó al lado una familia tranquila, imaginese que me hubiera tocado el del taller mecánico, ahí con el carrerio, (muchos autos) o el herrero, eso sí que no lo aguantaría" (Antonio, 37 años, residente de la tercera etapa).

Cuando le preguntamos a los encuestados sobre cómo era el trato que tenían con sus vecinos, el 44\% manifestó que era regular, siguiéndole un $25 \%$ con 


\section{FOTOS 3 Y 4 PROTECCIONES EN VIVIENDA Y ESPACIOS PÚBLICOS}

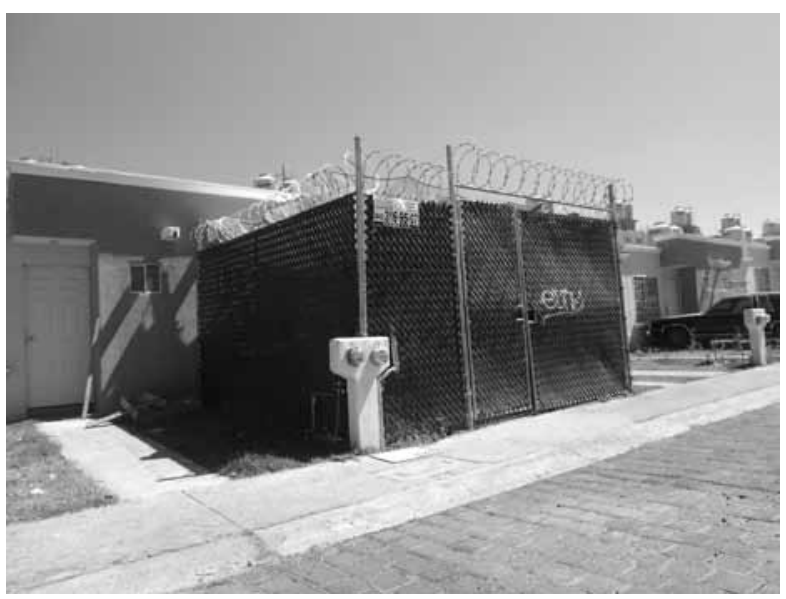

Fuente: Autores

una percepción de un mal trato, un 18\% calificó al trato como bueno y solo el $7 \%$ de muy bueno, el restante 6\% manifestó tener un trato muy malo con sus vecinos.

Por otra parte cuando les preguntamos a los encuestados sobre si conoce a los vecinos de su calle, el 58\% respondieron que no los conoce o que conoce a muy pocos, situación que propicia y es una muestra de la escasa participación en las juntas vecinales, en donde en algunos casos ni siquiera hay un organizador o jefe de manzana, y cuando sí lo hay, los vecinos no saben quién es (tabla 4).

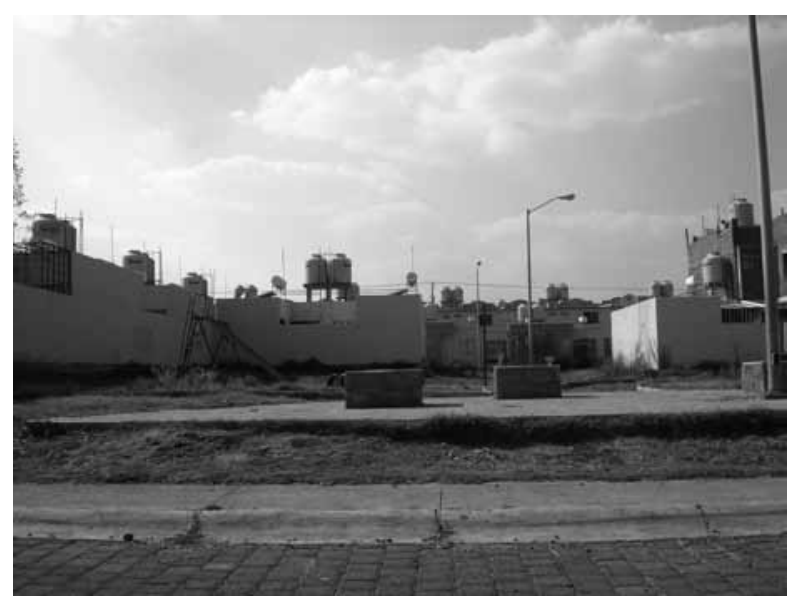

"[...] en una junta que asistí se acordó comprar silbatos, y cada que viéramos un asalto, robo, violencia o algo sospechoso tendríamos que silbar para que los vecinos oyeran y salieran todos a la calle, yo creo está bien ahora habrá que ver si se hace, porque somos pocos los que asistimos a las juntas y participamos" (Jorge, 38 años, residente de la primera etapa).

A la situación de que la mayoría de los encuestados conozca a pocos de sus vecinos, le añadimos que el 29\% sólo está más o menos conforme con las relaciones que ha establecido con ellos, el 23\% solo está conforme con algunas, el 20\% manifiesta indiferencia y el 12\% no está conforme, solamente 
el 14\% manifestó su conformidad, lo que muestra que no existen lazos solidarios entre ellos y en la mayoría de los casos la cotidianidad se vive como si los demás fueran extraños.

[...] los niños juegan aquí en la casa, muy de vez en cuando iban a esos juegos, pero yo los acompañaba para estarlos checando, como no conozco más que a mis vecinos de los lados, no vaya a ser, y luego dicen que se mete gente de otros lados aquí para hacer maldades, por eso prefiero que jueguen aquí en la casa, además mire los juegos ya están muy descuidados, el volantín esta clavado nada mas así en la tierra, sin cemento ni nada, hasta peligroso esta (Silvia, 34 años, residente de la cuarta etapa).

En este contexto, el uso del espacio tiende a reducirse cada vez más a la vivienda en contraposición de los espacios públicos, propiciando que las relaciones vecinales se limiten o sean nulas, pareciera así, que se diluye el concepto de civilidad, que Sennett ${ }^{51}$, interpreta como la capacidad de interactuar con extraños, de disfrutar la mutua compañía, aceptando su condición de extraños. La finalidad de la civilidad es proteger a los demás de la carga de uno mismo ${ }^{52}$. En Villas del Pedregal no se busca interactuar con extraños más bien se busca evitarlos, esto se demuestra en la escasa participación en las juntas vecinales y el desconocimiento de los organizadores de las mismas.

51 Sennett, 1978, p. 326-328.

52 Bauman, 2003, p. 102-104.
"Sinceramente no sé ni quién sea el jefe de manzana, unas cuadras tienen y otras no, aquí sí sé que hay uno y que alguna vez han hecho reuniones, me comentó la de aqui al lado que ella fue, pero que casi no fue gente, sabe si así las seguirán haciendo" (Selene, 29 años, residente de la cuarta etapa).

El Fraccionamiento Villas del Pedregal no escapa del proceso de segregación, y se constituye como un espacio estigmatizado, no son solo las condiciones de sus viviendas y su localización las que lo propician, sino tambien el limitado acceso a los equipamientos y servicios, las débiles relaciones vecinales, el escaso uso del espacio publico y la violencia e inseguridad. Estas ultimas se constituye como indicadores que tiende a amplificar la acumulación de desventajas urbanas que comparten los residentes del fraccionamiento.

"Pues hubo un caso muy sonado por los periódicos de un asesinato de un muchacho que al parecer se metieron a su casa varios sujetos y lo apuñalaron, y sí se supo por aquí, pero pues a nosotros no nos ha pasado nada gracias a Dios" (Rafael, 41 años, residente de la tercera etapa).

Fenómenos como la inseguridad, la violencia y el crimen son fuentes de miedo que tienen que ver con la manera cómo la gente percibe y vive en su cotidianidad estos problemas, así como con la escenificación que diariamente se hace de ellos a través de los medios de comunicación. El miedo de 
los residentes a la inseguridad tiene que ver con experiencias propias, pero también con experiencias ajenas como las descritas en los periódicos y las vividas por los vecinos del fraccionamiento.

\footnotetext{
"A nosotros gracias a Dios no nos ha pasado nada, pero si nos hemos enterado de que han robaron a algunos vecinos, que se han metido a su casa, y se han llevado muebles, a uno lo vaciaron la casa con un camión de mudanzas, fijese que yo si vi el camión, pero pues como iba a saber que estaban robando, desde que supe eso pusimos malla ciclónica" (Emilio, 38 años, residente de la tercera etapa).
}

El deterioro de la seguridad no se ha dado de manera homogénea ya que si bien la violencia letal no es la que más aqueja a la población del fraccionamiento y los delitos como robos a vivienda son los más comunes, la percepción de inseguridad en el fraccionamiento es evidente. De esto se desprende que los miedos no sólo son un modo de percibir el mundo, sino también una manera de estar, de habitar en él y relacionarse con las demás personas.

El acceso a espacios públicos de calidad contribuye a reducir la inseguridad y promueve la relación de los habitantes y la convivencia pacífica. Por otro lado, la inexistencia o la mala calidad de los mismos, propicia que la gente los perciba como peligrosos y se sienta insegura, una reacción ante esto es el protegerse y el no exponerse refugiándose en su viviend $a^{53}$.

53 Davis, 2001.

\section{Reflexiones finales}

La situación familiar de llegar a vivir a un entorno periférico, que no cuenta con todos los equipamientos y servicios, en donde no se sabe qué clase de personas tendrá como vecinos y en donde no tiene la certeza de que vayan a mejorar sus condiciones de vida, forma parte de las narrativas de los habitantes. En sus narrativas los habitantes vinculan experiencias pasadas, con experiencias presentes y con sus expectativas a futuro, de manera que muestran sus inconformidades y sus conformidades, sus sentimientos positivos y negativos y plasmas los obstáculos y las ventajas que se les presenta al habitar ese entorno habitacional.

La vinculación entre el tiempo presente, pasado y futuro forma parte de la narrativa y se hace presente cuando las personas narran sus experiencias al ser entrevistadas. Las respuestas a preguntas como ¿de dónde vienen y a dónde van? ¿Qué hacían, que hacen y que harán? ¿Qué esperan, que esperaban y que ya no esperan?, permiten acercarse al estudio de los modos de habitar en la vivienda, el fraccionamiento y la ciudad, en una relación inherente del individuo con la sociedad con la cual interactúa y de la que forma parte ${ }^{54}$

Por otra parte no podemos olvidar que en el habitar cotidiano no todos son acuerdos también los

54 Blumer, 1969. 
conflictos forman parte inherente de este $e^{55}$. En este sentido, señala Massey ${ }^{56}$, que existen identidades múltiples para cada lugar y que estas generan conflictos, ya que cada persona le da a su lugar diferentes usos y significados. También sugiere que en vez de pensar los lugares con fronteras definidas, podríamos imaginarlos como redes articuladas de relaciones sociales, experiencias y significados que tienen influencias globales que precisan constantes dentro de la diversidad del comportamiento social global ${ }^{57}$. Precisamente, una de estas constantes en Latinoamérica, es que se tiende a ser más crítico con la sociedad que con uno mismo. En las calificaciones que los individuos otorgan a las dimensiones de su vida como su trabajo, su vivienda, sus ingresos, etc., tienden a ser más benignos consigo mismos que con su ciudad o su país. Por ejemplo, según la encuesta Gallup del $2007^{58}$, se tiene que $83 \%$ de los mexicanos se muestra satisfecho con su vivienda, sin embargo sólo aproximadamente el $48 \%$ declaró estar satisfecho con la disponibilidad de viviendas de calidad y a un precio justo ${ }^{59}$.

Es un hecho que en algunos países, las personas valoran de manera más positiva su propia situación que

55 Lefebvre, 1978, p. 210.

56 Massey, 1991.

57 Massey, 2006.

58 La organización Gallup estableció un sistema de encuestas en 130 países incluyendo 22 países de Latinoamérica y el Caribe para recolectar información subjetiva sobre percepciones de calidad de vida

59

Lora, 2008, p. 18-21. la de los demás. De acuerdo con esto, la capacidad de las personas para valorar la vida no depende del todo de su ingreso, el tamaño de su vivienda o los servicios de su fraccionamiento, sino del grado en que consideren estar en mejor situación que la de los demás o que ellos mismos en el pasado. Es decir, que las personas hacen comparaciones sociales para la valoración de sus propias condiciones ${ }^{60}$, de esta manera si una persona vive en un entorno donde las viviendas están más pequeñas que la suya, que no deja de ser pequeña, tenderá a sentirse satisfecho, o por el contrario si tiene una vivienda más pequeña que la de sus vecinos, aunque esta sea grande, tenderá a sentirse insatisfecho. Esto también sucede a una escala espacial mayor, si la persona reside en un fraccionamiento equipado con mejores instalaciones que el fraccionamiento vecino se sentirá satisfecha o insatisfecha si las instalaciones son peores; estas situaciones también se dan en el tiempo, si una persona tenía un ingreso más bajo que el ingreso actual, aunque sigue estando mal pagado, esta condición negativa se aminora. Las personas dan cuenta de que sus vecinos o conocidos están en una peor situación económica, o de salud o tienen una vivienda más pequeña, y

60 Schneider y Schupp, 2014. 
tienden a sobrevaloran su propia situación, pensando en que podrían estar peor ${ }^{61}$.

Los argumentos anteriores formaron parte de las narrativas de los habitantes del fraccionamiento, ya que la mayoría manifestó haber mejorado su situación anterior y también considero que su fraccionamiento está en mejores condiciones que otros cercanos, aunque reconocen que sus viviendas, el equipamiento y servicios básicos tienen grandes deficiencias e incluso por momentos se sienten inseguros residiendo ahí. También reconocen que el alto costo de los traslados les dificulta visitar a familiares y amigos, y los limita a realizar solo los traslados necesarios, lo que debilita de sobremanera las redes de amistad y parentesco, a esto le aunamos que los recorridos en su mayoría son hechos por el padre, siendo las madres e hijos los que permanecen mayor tiempo en la casa. Esta situación nos hace reflexionar sobre el término ciudad dormitorio, ya que, no se trata de una ruptura con el lugar habitado de toda la familia, madres e hijos con todo y las deficiencias y demás impedimentos del fraccionamiento y la vivienda, permanecen ahí y no son actores pasivos, hacen evaluaciones personales, toman decisiones, se plantean retos y se formulan deseos que orientan sus prácticas cotidianas ${ }^{62}$.

En relación a lo anterior, al deseo inicial de los habitantes de tener "casa propia", que los llevó al fraccionamiento, se añadió el de "poner un negocio", como parte de la necesidad de subsistir ante la falta de empleo, además de la comodidad que representa trabajar en casa. De esta manera establecen una relación utilitaria con su vivienda y aunque sean espacios indiferentes y hasta rechazados, forman parte del habitar cotidiano.

El análisis de las narrativas del habitar, nos llevó a encontrar que algunas de las expresiones más usuales que manifiestan las razones por las que decidieron dejar su vivienda anterior, fueron, "para tener casa propia", "para progresar", "para tener calidad de vida", "porque tenía un crédito", "para independizarme", entre otras, que se contraponen con las expresiones referentes a su estancia y permanencia en el lugar como, "estamos por mientras", "llegamos porque no había mejor opción", "quiero rentar la casa", "sólo estamos por un rato", "llevo rato que me quiero cambiar", etc. Al 72\% de los encuestados no les interesa proyectar un futuro allí, valoran la vivienda sobretodo en su calidad de propiedad, pero no valoran la posibilidad de quedarse ahí, y forjar un futuro familiar en ese entorno.

No podríamos entender cómo valoran las personas el entorno en que viven desde la única visión de los planificadores y los promotores inmobiliarios. La planificación urbana como herramienta para la intervención urbana no puede ser eficaz si no considera lo que la gente siente y necesita en el entorno

61 Diener y Biswas-Diener, 2002.

62 Hiernaux y Lindón, 2004. 
que habita cotidianamente. La valoración que tienen los habitantes sobre su entorno habitacional, no se puede entender al margen de los procesos que provocan precisamente esta valoración. Los habitantes pueden sentir miedo en el fraccionamiento porque hay muchos asaltos, pueden pensar que su vivienda es muy pequeña porque no hay espacio para sus muebles, pueden sentir que el fraccionamiento está muy alejado porque ocupan mucho tiempo en llegar a su destino, pueden pensar que el fraccionamiento no tiene el equipamiento necesario porque necesitan salir de este para hacer sus compras, pueden sentir y pensar muchas cosas acerca de su vida en ese lugar, y si no se conocen las razones del porque piensan y sienten así, no es posible tener los elementos para hacer las intervenciones urbanas propicias para que los habitantes hagan de estos espacios lugares para habitar.

\section{Bibliografia}

ÁBALOS, Iñaki. La buena vida: visitas guiadas a las casas de la modernidad. Barcelona, Gustavo Gili. 2005. ISBN 978-84-252-1829-3.

ACEBO IBÁÑEZ, Enrique del. Sociología del arraigo: una lectura crítica de la teoría de la ciudad. Buenos Aires, Claridad. 1996. ISBN 950-620-108-0.

AGNEW, John. Space: Place. En: CLOKE, Paul, ed. y JOHNSTON, Ron, ed. Spaces of geographic thought. Deconstructing human geography's binaries. London, Sage. 2005. ISBN 0-7619-4731-0.
ARFUCH, Leonor. La vida como narración. En: ARFUCH, Leonor. El espacio biográfico. Dilemas de la subjetividad contemporánea. Buenos Aires, Fondo de Cultura Económica. 2010.

BACHELARD, Gaston. La poética del espacio. México, Fondo de Cultura Económica. 2000. ISBN 950-557-354-5.

BAILLY, Antoine. Lo imaginario espacial y la geografía. En defensa de la geografía de las representaciones. Anales de Geografía de la Universidad Complutense. 9: 11-19, 1989. ISSN 0211-9803.

BAUMAN, Zygmunt. Modernidad líquida. Buenos Aires, Fondo de Cultura Económica. 2003. ISBN 950-557-513-0.

BECK, Ulrich. La sociedad del riesgo. Hacia una nueva modernidad. Buenos Aires, Paidós. 1998. ISBN 84-493-0406-7.

BERGER, Peter y LUCKMANN, Thomas. La construcción social de la realidad. Buenos Aires, Amorrortu. 2001.

BLUMER, Herbert. Symbolic interactionism: perspective and method. California, University of California Press. 1969. ISBN 0-520-05676-0

BLUNT Alison y DOWLING, Robyn. Home (key ideas in Geography). London, Routledge. 2006. ISBN 0-415-33275-3.

DAIUTE, Colette y LIGHTF00T, Cynthia. Theory and craft of narrative analysis. En: DAIUTE, Colette, ed. y LIGHTFOOT, Cynthia, ed. Narrative analysis. Studying the development of 
individuals in society. California, Sage. 2004. ISBN 0-7619-2797-2.

DAVIS, Mike. Control urbano: la ecología del miedo. Barcelona. Virus Editorial. 2001.

DE BOTTON, Alain. The Architecture of happiness. New York, Pantheon Books. 2006. ISBN 0-375$42443-1$.

DIENER, Ed y BISWAS-DIENER, Robert. Will money increase subjective well being? [En línea]. Social Indicators Research. 57(2): 119-169, 2002. ISSN 0303-8300. Disponible en: http://dx.doi. org/10.1023/A:1014411319119

DUHAU, Emilio y GIGLIA, Angela. Las reglas del desorden: habitar la metrópoli. México, Siglo XXI, UAM- Azcapotzalco. 2008. ISBN 978-968-23-2760-5.

EKAMBI-SCHMIDT, Jézabelle. La percepción del hábitat. Barcelona, Gili. 1978. ISBN 978-8425208003.

GIANNINI, Humberto. La reflexión cotidiana. Santiago de Chile, Universitaria. 1987. ISBN 956-11-1720-7.

GIDDENS, Anthony. La constitución de la sociedad. Buenos Aires, Amorrortu. 2006.

GILI GALFETTI, Gustau. Mi casa, mi paraíso. Barcelona, Gili. 1999. ISBN 978-8-4252-1789-0.

GOBIERNO Municipal de Morelia. Plan municipal de desarrollo, Morelia. 2012 -2015.
GUBRIUM, Jaber F. y HOLSTEIN, James. Narrative ethnography. En: HESSE-BIBER, Sharlene, ed. y LEAVY, Patricia, ed. Handbook of emergent methods. New York, Guilford Publications. 2008. ISBN 978-1-59385-147-7.

HARDT, Michael y NEGRI, Antonio. Empire. Cambridge, Massachusetts, Harvard University Press. 2000. ISBN 0-674-25121-0.

HEIDEGGER, Martin. Construir, habitar, pensar. En: Conferencias y artículos. Barcelona, Serbal. 1994. ISBN 84-7628-143-9

HERNÁNDEZ, Roberto; FERNANDEZ, Carlos y BAPTISTA, Pilar. Metodología de la investigación. México, McGraw Hill. 2006

HIERNAUX, Daniel, ¿Identidades móviles o movilidad sin identidad? El individuo moderno en transformación. Revista de Geografía Norte Grande. (34): 5-17, 2005. ISSN 0718-3402.

HIERNAUX, Daniel y LINDÓN, Alicia. Repensar la periferia: de la voz a las visiones exo y egocéntricas. En: AGUILAR, Adrián Guillermo, coord. Procesos metropolitanos y grandes ciudades: dinámicas recientes en México y otros países. México, Instituto de Geografía, CRIM-UNAM, Miguel Ángel Porrúa. 2004. p. 413-443.

HOLLOWAY, Lewis y HUBBARD, Phil. People and place: the extraordinary geographies of everyday life. Harlow, Pearson Education. 2001. ISBN $0-582-38212-2$. 
LEFEBVRE, Henry. Everyday life in the modern world. New York, Harper and Row. 1971. ISBN 06-131608-3.

----- De lo rural a lo urbano. Barcelona, Península. 1978. ISBN 84-297-0910-X.

LINDÓN, Alicia. El mito de la casa propia y las formas de habitar. [En línea]. Scripta Nova. Revista electrónica de geografía y ciencias sociales. IX(194-20), 2005. ISSN 1138-9788. [Fecha de consulta: 17 agosto 2012]. Disponible en: http://www.ub.es/ geocrit/sn/sn-194-20.htm

----- Geografías de la vida cotidiana. En: HIERNAUX, Daniel, dir. y LINDÓN, Alicia, dir. Tratado de geografía humana. Barcelona, AnthroposUniversidad Autónoma Metropolitana. 2006.

---- Los imaginarios urbanos y el constructivismo geográfico: los hologramas espaciales. [En línea]. EURE. 33(99): 31-46, agosto 2007. ISSN 0717-6236. [Fecha de consulta: 24 abril 2012]. Disponible en: http://dx.doi.org/10.4067/ S0250-71612007000200004.

LORA, Eduardo, coord. Calidad de vida: mas allá de los hechos. Washington D.C., Banco Interamericano del Desarrollo. 2008. ISBN 978-1-59782-083-7.

MASSEY, Doreen. A global sense of place. Marxism Today. p. 24-29, junio 1991.

----- Lugar, identidad y geografías de la responsabilidad en un mundo en proceso de globalización. Treballs de la Societat Catalana de Geografia. (57): 77-84, 2004.
-..-- For space. London, Sage. 2006. ISBN 978-1-4129-0361-5.

MILLER, Daniel. Home possessions: material culture behind closed doors. Oxford, Berg. 2001. ISBN 1-85973 585-1.

MONTEYS ROIG, Xavier y FUERTE PEREZ, Pere. Casa collage, un ensayo sobre la arquitectura de la casa. Barcelona, Roselló, Gustavo Gili. 2003. ISBN 84-252-1869-1.

ORTIZ, Víctor. La casa, una aproximación. México, UAM-Xochimilco. 1984. ISBN 968 - 597498-5.

SACK, Robert David. Homo geographicus: a framework for action, awareness, and moral concern. Baltimore, Johns Hopkins University Press. 1997. ISBN 0-8018-5553-5.

SCHNEIDER, Simone y SCHUPP, Jurgen. Individual differences in social comparison and its consequences for life satisfaction: introducing a short scale of the Iowa-Netherlands comparison orientation measure. [En línea]. Social Indicators Research. 115(2): 767-789, 2014. ISSN 03038300. Disponible en: http://dx.doi.org/10.1007/ s11205-012-0227-1.

SCHUTZ, Alfred. Estudios de teoría social. Buenos Aires, Amorrortu. 2003. 288 p. ISBN: 978-950-518-231-2.

SCHUTZ, Alfred y LUCKMANN, Thomas. Las estructuras del mundo de la vida. Buenos Aires, Amorrortu. 1977. ISBN 978-950-518-065-3. 
SENNETT, Richard. El declive del hombre público. Barcelona, Península. 1978. ISBN 84-297-1445-6.

TAYLOR, Charles. Imaginarios sociales modernos. Barcelona, Paidos. 2006. 226 p. ISBN: 84-493-1899-8.

TUAN, Yi-Fu. Space and place: the perspective of experience. Minneapolis, University of Minnesota. 2001. ISBN 0-8166-3877-2.

UZCATEGUI ARAÚJO, Judit. El imaginario de la casa en cinco artistas contemporáneas: Remedios Varo, Louise Bourgeois, Marjetica Potrc, Doris Salcedo y Sydia Reyes. Madrid, Eutelequia. 2011. ISBN 978-84-938256-1-4.

WESTBURY, Philippa. A sense of place, what residents think of their new homes. London, CABE Commission for Architecture and the Built Environment. 2007. 